\title{
Early Osseointegration Attained by UV-Photo Treated Implant into Piezosurgery-Prepared Site Report II. Influences of Age and Gender
}

\author{
Takashi Miyazaki*, Tomohiro Yutani, Nanae Murai, Aya Kawata, Haruka Shimizu, Naru Uejima and Yukiko Miyazaki \\ Miyazaki Dental Clinic, Kashiba-City, Nara Prefecture, Japan
}

*Corresponding author: Takashi Miyazaki, Director, Miyazaki Dental Clinic, Kashiba-City, Nara Prefecture, Japan, E-mail: miyarin3366@gmail.com

Received: 13 Jan, 2021 | Accepted: 19 Jan, 2021 | Published: 25 Jan, 2021

Citation: Miyazaki T, Yutani T, Murai N, Kawata A, Shimizu H, et al. (2021) Early Osseointegration Attained by UV-Photo Treated Implant into Piezosurgery-Prepared Site Report II. Influences of Age and Gender. Int J Dent Oral Health 7(2): dx.doi.org/10.16966/2378-7090.351

Copyright: (C2021 Miyazaki T, et al. This is an open-access article distributed under the terms of the Creative Commons Attribution License, which permits unrestricted use, distribution, and reproduction in any medium, provided the original author and source are credited.

\begin{abstract}
Purpose: The aim of this retrospective study was to examine the effects of age and gender on ISQ scales on 75 implant patients who received the UV photo functionalized implants, which were placed into piezosurgery-prepared site.

Methods: Total 75 cases were subjected to this study. All placed implants were made of commercially pure titanium (grade IV), which were originally surface treated by sandblasting followed by an acid etching. Diameter was ranged from $3.3 \mathrm{~mm}$ to $5.0 \mathrm{~mm}$, while length varied from $7.0 \mathrm{~mm}$ to 11.5 $\mathrm{mm}$. These original implants were UV photofunctioned and were placed into previously prepared sites by the piezosurgery technique. ISQ scale was measured at implant placement (prior to suturing). ISQ scale was also measured at initial loading after certain days from the implant placement. Changes in the differences between these two ISQ scale readings were related to days between implant placement and loading (in other words, healing time). ISQ scale data were further subjected to analyze the effects of age and gender. No statistic studies were made.

Results: There appears to be two distinctive relations between changes in ISQ scale and healing time; namely, one trend indicates that there are not noticeable changes and remain initial ISQ scale measured at the implant placement, and the other relation exhibits a remarkable increase in ISQ during the healing process. Number of female elderly patients was higher than aged male patients. The above two distinctive relationships appear to be common in both male and female implant patients. There seems to be a criterion of required ISQ scale to achieve successful implant treatment and ISQ scale should be at least 60 when an initial loading starts.

Conclusions: Within limited number of implant patient cases, it was concluded that (i) UV surface alteration and enough blood supply by piezosurgery preparation exhibited synergistic effects on improvement of ISQ scales, indicating that these dual techniques appears applicable to implant treatments, (ii) number of elderly female implant patients were more than male patients, (iii) ISQ scales increased during the bone healing stage for both male and female patients, and (iv) there is a critical value of ISQ for successful implant treatment and it is at least 60 . Based on these findings, we prefer to take our standard for implant treatment to be "semi-early loading", indicating that the loading can be started sometime between one and two months after the implant placement.
\end{abstract}

Keywords: Commercially pure titanium grade IV implant; SA treatment; ISQ scale; Semi-early loading; UV photofunctioning; Piezosurgery

\section{Introduction}

In our previous paper [1], synergistic effects of UV photofunctionalization on titanium implant surface and the piezosurgery-prepared site for implant placement were evaluated in terms of ISQ scales as a measure of placed implants' stability. From analyses on 35 clinic cases, it was found that UV surface alteration and enough blood supply by piezosurgery preparation exhibited synergistic effects on improvement of ISQ scales, making the assured loading timing, and even lowers the ISQ scale during the bone healing stage; they are still acceptable level for pursuing early loading. Since bone metabolism (or bone healing) is slow among aged patients and bone density level could differ between male and female patients, this difference could be furthermore emphasized among aged patients. Accordingly, in this paper, 40 additional cases are added to 35 cases (partially reported in previous paper [1]), so total 75 cases are subjected to analyze influences of age and gender on ISQ scales at implant placement and initial loading.

Gender plays a significant role in influencing bone density, which describes the quality of bone, and when age is considered, there are significant gender-related differences in bone mineral density [2]. Although man and woman possess a similar level of protein matrix per unit of segment volume, woman exhibits significantly less bone mineral to their skeletons [3], due to lower calcium content per skeleton and possible post-menopausal changes when they enter this age zone. Post-menopausal women are particularly vulnerable to osteoporosis because of the loss of estrogen associated with menopause. As estrogen decreases, there is an increase of cytokines (either directly or indirectly) that regulate osteoclasts [3]. Clinical 
osteoporosis is more commonly observed in women [4,5]. As to implant survival rates between male and female patients, there appears to be no difference in implant success based on gender $[6,7]$.

Lin G, et al. [8] used the multivariate generalized estimating equation (GEE) logistic regression method to identify risk factors related to both early and late implant loss on total of 18,199 patients received 30,959 dental implants. Multivariate's included age, gender, jaw, location, implant brands, implant length and diameter, bone augmentation procedures, and the number of implants placed per patient. It was reported that GEE showed that (i) general factors such as male gender, elderly patients, mandibular anterior location, bone augmentation and short implants were associated with implant loss and (ii) male patients aged older than 41 years, and mandibular anterior location were risk factors for early implant loss. In order to evaluate bone changes around endosseous implants in partially edentulous patients, 252 patients receiving total of 632 two-stage implants were subjected to assess the bole levels on orthopantomography immediately after surgery and after 36 months and marginal bone loss (MBL) was calculated from their difference [9]. It was mentioned that (i) MBL progressively increased with age in male patients but reached a peak already in the $50-60$ years age group in the female subjects and (ii) the overall MBL is consistent with the available literature. Site difference and patient age and gender appear to significantly affect MBL, representing important factors to be considered during implant placement.

Synergistic effects of UV photofunctionalization and piezosurgery were recognized in our previous study [1]. A specific aim of this retrospective study was to analyze dual effects under influences of age and gender variations in terms of the ISQ (implant stability quotient) scale as a measure of the implant stability. ISQ scale at implant placement and ISQ scale at early loading are measured and the differences between these scales could provide a promising indicator for healthy bone healing and the onset timing of loading (Table 1).

\section{Materials and Methods}

\section{Materials}

In the previous study, total 35 implants were placed, in which 33 implants were Osstem TS3 SA and 2 implants were Straumann Bone Level SLA. SA indicates that the implant surface was SAed (sand blasted with alumina particle, followed by an acid etching), while SLA means similarly that the surface of implants was subjected to sand blasted with large alumina grits, followed by acid etching. In this study, total 40 implants were placed, in which 31 Osstem implants (TS3, SS3) and 2 Shofu implants were SAed, and 7 Straumann implants (BLT, BL and TE) were SLAed. All implants were made of CpT (commercially pure titanium) Grade IV. Diameter of all implants is larger than 4.0 $\mathrm{mm}$ and lengths are in a range from 7 to $8 \mathrm{~mm}$.

\section{UV photofunctionalization}

For treating implant surfaces, the commercially available Thera BeamAffiny UV system was employed for 15 minutes for an automatic program of UV exposure, followed by the implant placement procedure.

\section{Piezosurgery}

Mectron Piezosurgery 2 system (Mectron SPA, Carasco, Italy) was utilized. The average operation time was about 15 minutes including exchanging times of 4 to 5 insert chips. The load that patients can feel is so light that this operation normally does not provide any unnecessary anxiety on patients. The implant placement was performed by routine procedure which should be a common practice regardless of surface conditions of implants and implant placement site preparation.

\section{ISQ scale evaluation}

The ISQ (implant stability quotient) is the value on a scale, indicating the level of stability and osseointegration in dental implants and is obtained using resonance frequency analysis (RFA) $[10,11]$. In this study, the OSSTELL ISQ system was used. The ISQ scales were measured at two directions, namely lingual and buccal sides. In table 2, a pair (for example, $80-80$ for case No.1) indicates ( 80 measured at lingual side -80 obtained at buccal side) ISQ scale data. ISQ scale measurements were conducted at immediate after implant placement (even before the suturing), designed as ISQ@I, and at the time of first loading, designed as ISQ@L, respectively. In addition, the changes in ISQ scales between ISQ@I and ISQ@L should indicate an overall stability of placed implants, the change rates $(=[\Delta \mathrm{ISQ} / \mathrm{ISQ} @ \mathrm{I}] \times 100$ in \%) are also analyzed and proposed here to provide a useful implant stability indicator.

\section{Results}

For summary analysis purpose, data from table 1 was copied from our previous study [1]. The additional data sources are presented in table 2. For tables, the following notations are used:

1) ISQ@I: ISQ scale was measured at immediately after implant placement before suturing.

2) Load: after certain days (as marked under "Days bet. I/L), loading was conducted.

3) ISQ@L: ISQ scale was measured upon loading.

4) $\triangle$ ISQ: the differences of ISQ scale between two readings: $\Delta \mathrm{ISQ}=\mathrm{ISQ} @ L-I S Q @ I$.

5) $\triangle \mathrm{ISQ}$ rate: for normalizing baseline, the $\triangle \mathrm{ISQ}$ rate was obtained by $[\Delta \mathrm{ISQ} / \mathrm{ISQ} @ \mathrm{I}] \times 100(\%)$.

Total 75 cases ( 35 cases in previous paper +40 cases in this study) are presented in ages and gender as illustrated in figure 1, in which there are 21 male patients and 54 female patients. As to an age distribution, we divided into two groups: younger than 65 years old (total 37patients $=17$ male +20 female) and aged over 65 years old (total $38=4$ male +34 female). The reason for setting the age of 65 to separate two age groups is based on the fact that the age of 65 is one of commonly accepted age criterion for entering aging society. In this study, it was found that there was an equally divided age groups in younger and older than the 65 -criterion.

Figure 2 illustrates $\triangle I S Q$ rate in terms of days after implant placement till the initial loading. It appears to be that there are two distinctive groups in this graph; (i) a group which did not exhibit remarkable changes in ISQ scales, marked with dotted-red circle, and (ii) a group shows an increasing trend of ISQ scales during the healing period, marked with dotted-blue circle. These trends are normalized among gender difference and age difference.

\section{Discussion}

From figures 1 and 2, it seems to be that the needs from elderly women for implant treatments are more demanded. Their healing manner is also varied and clearly can be divided into two tendencies; one group showed remarkable increase in ISQ value during the bone healing period, and other trend exhibits no changes during an entire healing process. Relatively speaking, female patients younger than the 65-year-old criterion show an increment tendency in ISQ values within 2-month healing stage. When occlusion is loaded the placed implant, it is the bone to bear the occlusal force. The implant placed at mandibular jaw may be in contact with the dense bone on the 
Table 1: Summary of obtained data in terms of loading date, implant dimension and location, ISQ at placement and loading date and ISQ at loading [1].

\begin{tabular}{|c|c|c|c|c|c|c|c|c|c|c|}
\hline No. & Implant 2014 & Loc & Size $(\mathrm{mm})$ & ISQ@I & Load & ISQ@L & Days bet. I/L & $\Delta I S Q$ & $\Delta I S Q$ rate (\%) & ISQ-A \\
\hline 1 & $03 / 14$ & 45 & $4.5 \times 7.0$ & & $04 / 28$ & $77-77$ & 34 & & & $78-78(05 / 09)$ \\
\hline 2 & $03 / 27$ & 44 & $4.0 \times 10.0$ & & & & 58 & & & \\
\hline 3 & $03 / 27$ & 46 & $4.0 \times 11.5$ & & & & 58 & & & \\
\hline 4 & $03 / 27$ & 46 & $4.5 \times 8.5$ & $U$ & $06 / 24$ & $62-59$ & 66 & & & \\
\hline 5 & $03 / 28$ & 45 & $4.5 \times 8.5$ & $71-71 \mathrm{G}$ & $06 / 12$ & $58-58$ & 76 & -13 & -18.3 & $18-18(05 / 20)$ \\
\hline 6 & $03 / 28$ & 46 & $4.5 \times 8.5$ & $83-83$ & $06 / 12$ & $83-83$ & 76 & 0 & 0 & $75-75(05 / 20)$ \\
\hline 7 & $03 / 29$ & 44 & $4.0 \times 10.0$ & & $05 / 24$ & $75-75$ & 57 & & & \\
\hline 8 & $03 / 29$ & 46 & $5.0 \times 10.0$ & & & & 57 & & & \\
\hline 9 & $04 / 03$ & 26 & $5.0 \times 8.5$ & $68-68 \mathrm{U}$ & $05 / 30$ & $70-69$ & 57 & 1 & 5.9 & \\
\hline 10 & $04 / 05$ & 25 & $5.0 \times 8.5$ & $48-52 \mathrm{~S}$ & $05 / 24$ & $71-70$ & 49 & 20 & 40.0 & $80-80(06 / 28)$ \\
\hline 11 & $04 / 05$ & 22 & $3.5 \times 10.0$ & & 06/06 & $64-64$ & 62 & & & \\
\hline 12 & $04 / 11$ & 21 & $4.0 \times 10.0$ & $67-67$ & $05 / 26$ & $74-74$ & 55 & 7 & 10.4 & \\
\hline 13 & $04 / 11$ & 44 & $4.5 \times 8.5$ & $75-75$ & $05 / 13$ & $75-75$ & 32 & 0 & 0 & \\
\hline 14 & $04 / 11$ & 46 & $4.5 \times 8.5$ & $72-72$ & $05 / 13$ & $72-72$ & 32 & 0 & 0 & \\
\hline 15 & $04 / 17$ & 46 & $4.5 \times 8.5$ & & & & 37 & & & \\
\hline 16 & $04 / 18$ & 35 & $4.0 \times 10.0$ & $80-79$ & $05 / 22$ & $77-77$ & 34 & -3 & -3.8 & \\
\hline 17 & $04 / 18$ & 36 & $4.5 \times 8.5$ & $84-80$ & $05 / 22$ & $80-80$ & 34 & 0 & 0 & \\
\hline 18 & $04 / 24$ & 33 & $4.0 \times 8.5$ & $81-81$ & 06/09 & $83-83$ & 46 & 2 & 2.4 & \\
\hline 19 & $04 / 24$ & 35 & $4.0 \times 8.5$ & $69-69$ & 06/09 & $73-73$ & 46 & 3 & 4.3 & \\
\hline 20 & $05 / 13$ & 37 & $5.0 \times 8.5$ & $80-80$ & $06 / 21$ & $77-82$ & 21 & 0 & 0 & \\
\hline 21 & $05 / 15$ & 46 & $4.8 \times 8.0$ & $77-82$ & $06 / 24$ & $84-85$ & 40 & 5 & 6.3 & \\
\hline 22 & $05 / 16$ & 24 & $4.5 \times 8.5$ & $70-71$ & $06 / 18$ & $70-72$ & 33 & 0 & 0 & $71-71(07 / 02)$ \\
\hline 23 & $05 / 29$ & 23 & $4.0 \times 10.0$ & $61-61$ & $07 / 10$ & $76-76$ & 42 & 15 & 24.6 & \\
\hline 24 & $05 / 31$ & 35 & $4.0 \times 11.5$ & $79-79$ & $06 / 21$ & $75-78$ & 21 & -2 & -2.5 & \\
\hline 25 & $06 / 07$ & 14 & $4.5 \times 11.5$ & $75-76$ & $07 / 05$ & $75-71$ & 33 & -1 & -3.9 & \\
\hline 26 & $06 / 07$ & 16 & $4.5 \times 8.5$ & $69-70 \mathrm{~S}$ & $07 / 05$ & $63-70$ & 33 & -1 & -1.4 & \\
\hline 27 & $06 / 12$ & 45 & $4.5 \times 8.5$ & $62-61$ & $07 / 08$ & $61-68$ & 26 & 0 & 0 & $72-72(07 / 14)$ \\
\hline 28 & $06 / 12$ & 46 & $4.5 \times 8.5$ & $82-82$ & $07 / 08$ & $82-82$ & 26 & 0 & 0 & $82-82(07 / 14)$ \\
\hline 29 & $06 / 28$ & 31 & $3.5 \times 10.0$ & $44-49 \mathrm{G}$ & $08 / 22$ & $62-62$ & 55 & 15 & 31.9 & \\
\hline 30 & $07 / 03$ & 44 & $4.0 \times 8.5$ & $80-80$ & $08 / 22$ & $75-75$ & 50 & -5 & -6.3 & \\
\hline 31 & $07 / 03$ & 46 & $4.5 \times 8.5$ & $71-70$ & $08 / 22$ & $82-82$ & 50 & 10 & 14.1 & \\
\hline 32 & $07 / 05$ & 22 & $3.5 \times 10.0$ & $63-60 \mathrm{G}$ & $08 / 21$ & $70-70$ & 47 & 8 & 13.0 & \\
\hline 33 & $07 / 10$ & 22 & $3.3 \times 10.0$ & & $08 / 20$ & $63-63$ & 41 & & & \\
\hline 34 & $07 / 17$ & 24 & $4.0 \times 10.0$ & $64-65$ & $08 / 21$ & $65-65$ & 35 & 1 & 1.5 & \\
\hline 35 & $07 / 17$ & 26 & $4.5 \times 8.5$ & 59-61 UP & 09/09 & $65-65$ & 54 & 5 & 8.3 & \\
\hline
\end{tabular}

Note: U: remaining bone thickness is less than $4 \mathrm{~mm}$; G: bone grafting material was applied; S: socket floor elevation was performed; P: platelet-rich fibrin was applied

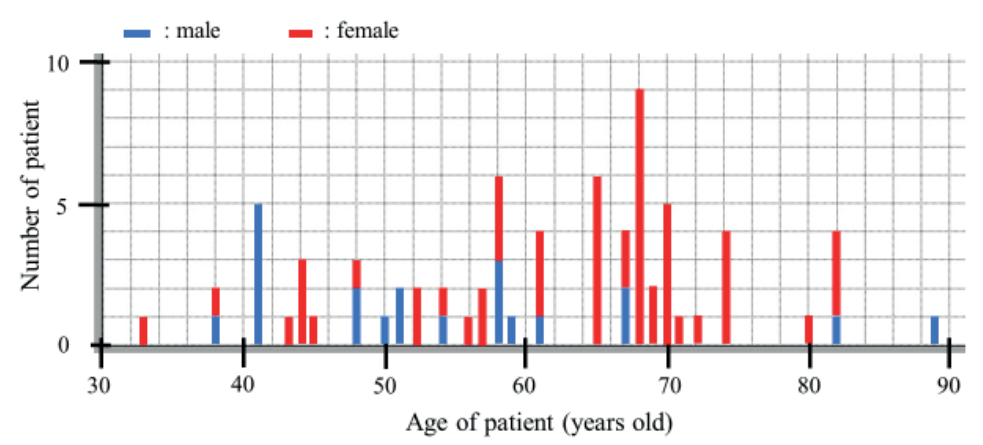

Figure 1: Patient distribution in terms of gender and age. 


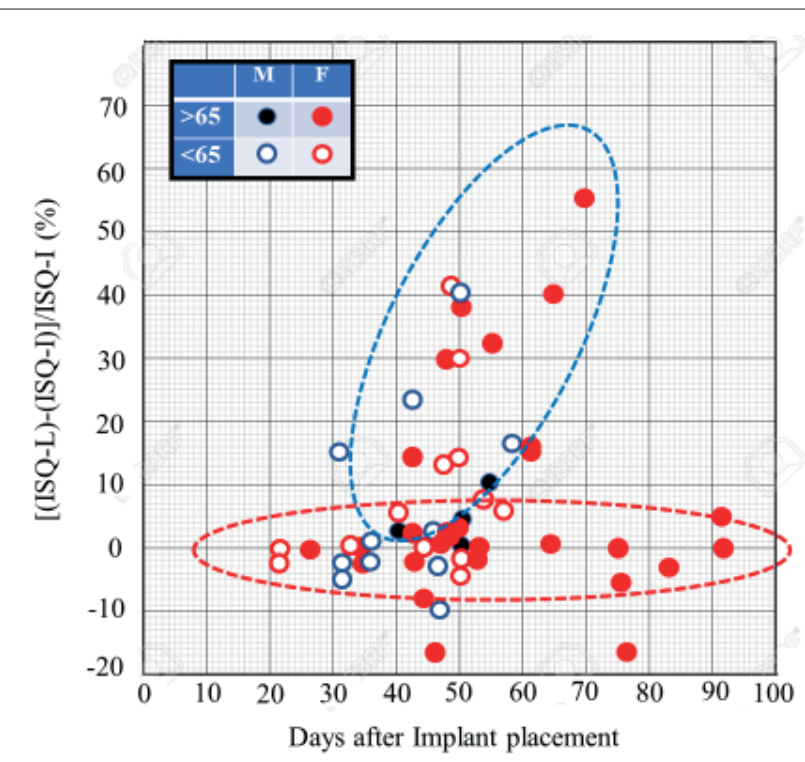

Figure 2: Changes in ISQ scales between implant placement and loading as a function of healing days between implant placement and initial loading.

buccal-lingual surface of the neck or fixture, resulting in that the occlusal load-bearing capacity after obtaining the osseointegration is relatively easy to obtain. However, if the buccal-lingual width of the bone is large even in the mandibular jaw and the fixture does not touch the dense bone, or in most of the cases with maxillary jaw, the implants will be supported by spongy cancellous bone. This indicates that the available quantity of cancellous bone should be directly related to the occlusal load-bearing capacity. Therefore, implant treatability should be evaluated by examining bone quantity of planned area for implant treatment. If available bone quantity is not enough and the inadequate quality of bone, advanced bone forming technique will be available to establish satisfactory osseointegration. However, there could be a potential risk for bone failure around the placed implant in a longterm usage. Hence, it should be noted that the actual bone quantity per unit surface area (in other words, the surface area of bone in contact with the implant at the implant placement) is less than that judged by the three-dimensional image method [12]. Although bone quality clearly can affect integration rates, additional variables (such as the implant surface conditioning) can also influence a long-term implant performance success. Stach RM, et al. [13] examined outcomes of clinical studies on monitoring the performance of machined-surfaced implants and dual acid-etched Osseotite implants isolating the effect of bone quality and implant surface conditioning. It was reported that (i) for the machined-surfaced implants, the 4-year CSR (cumulative success rate) in all bone sites is $92.7 \%$, (ii) for the implants placed in good (dense and normal) bone, the 4 -year CSR is $93.6 \%$ compared with the 4-year CSR in poor (soft) bone of $88.2 \%$, and (iii) for Osseotite implants in all sites, their overall 4 -year CSR was $98.4 \%, 98.4 \%$ in good bone, and $98.1 \%$ in poor bone; concluding that bone quality therefore seems to have a definitive impact on machined-surfaced implants, but this effect was not observed in the Osseotite implant series. On the other hand, Bahat $\mathrm{O}$, et al. [14] reviewed a large series of Brånemark system implants placed in posterior maxillae (660 implants in 202 patients) that have been restored with fixed partial porcelain-fusedto-metal (PFM) restorations and followed for as long as 12 years after loading. Thirteen of the implants (2\%) failed between placements and loading, 12 implants were lost between loading and the end of the first year, and 10 failed thereafter, 2 as the result of fractures at 3 and 4 years. It was mentioned that (i) the CSR is $94.4 \%$ at 5 to 6 years and $93.4 \%$ after 10 years, (ii) the quality and quantity of bone appeared to have little influence on the success rate, (iii) surgical techniques are particularly important to the success of osseointegrated implants placed in the posterior maxilla and (iv) with careful surgical planning and execution, a success rate of approximately $95 \%$ at 5 years can be achieved.

There is always debate between immediate loading and early loading. Although no clear definitions for both terms can be found, according to numerous reported publications, it can be said that (1) if superstructure is installed within 48 hours in post-operation period, it can be called as an immediate loading, (2) if it is installed within 1 or 2 weeks, it can be considered as an early loading, and (3) if it is installed after a couple of months, it should be a normal (or delayed) loading.

Chiapasco $\mathrm{M}$, et al. [15] conducted a multicenter retrospective study on 226 patients necessitating an implant-supported overdenture in the lower jaw. The patients were provided with 904 osseointegrated implants inserted in the interforaminal region of the mental symphisis (4 implants per patient). Immediately after implant placement, a U-shaped gold bar was fabricated and implants were immediately loaded with an implant-retained overdenture. It was reported that out of 226 patients treated, 194 were followed from a minimum of 2 years to a maximum of 13 years, with a mean follow-up of 6.4 years, whereas 32 patients dropped out during follow-up. The overall failure rate of implants was 3.1\% (24/776 implants), whereas the failure rate of bars was $1.5 \%$ (3/194 bars). Based on these findings, it was concluded that (i) the success rate of immediately loaded implants was similar to that obtained in the case of delayed loading, after osseointegration has taken place and (ii) in contrast, this method shortens dental rehabilitation times with relevant satisfaction for patients [15]. The conclusion was supported and confirmed by Gatti C, et al. [16], Kinsel RP, et al. [17] and Fischer K, et al. [18]. In order to reach a successful result on the immediate loading, as Esposito M, et al. [19,20] pointed out, a certain initial fixation is a sine-quo-non along with precisely fabricated superstructure with high rigidity.

On the other hand, Romanos GE, et al. [21] evaluated the clinical success of immediately loaded implants versus implants loaded in a delayed fashion in the posterior mandible. Three implants were placed distal to the canines bilaterally in the edentulous distal mandibular ridges of 12 patients. One side was randomly selected for placement of three implants (delayed loading; control sites) with a progressive thread design for submerged healing, and after 3 months the implants were exposed and loaded with provisional splinted crowns, which were replaced 6 weeks later by the definitive restorations. Three additional implants (immediately loaded; test sites), of the same size were placed in the contralateral side of the mandible. It was reported that (i) after a mean loading period of 25.3 months, the patients showed normal mean clinical values without significant differences $(\mathrm{P}<0.05)$ for test and control implants, respectively and (ii) after 2 years of loading in the posterior mandible, test and control implants had the same prognosis. Such conclusive remarks were confirmed by other reports [22-25].

As we have seen in the above, there can't be found any definite answer which is the best among immediate loading, early loading and delayed loading. In any event, because elderly patients need a certain type of a bone management such as bone grafting, which requires additional healing time? Accordingly, it is our implant treatment policy not to pursue the immediate loading. 
Table 2: Summary of obtained data in terms of patient information, loading date, implant dimension and location, ISQ scales implantation and loading (this study).

\begin{tabular}{|c|c|c|c|c|c|c|c|c|c|c|}
\hline No. & Implant 2018 & Loc. & Type & Age & Sex & ISQ@I & Days bet. I/L & ISQ@L & $\Delta \mathrm{ISQ}$ & $\Delta \mathrm{ISQ}$ rate (\%) \\
\hline 1 & $08 / 24$ & 45 & TS3 & 59 & $\mathrm{M}$ & $80-80$ & 49 & $81-87$ & 4 & 5.0 \\
\hline 2 & $08 / 25$ & 25 & TS3 & 65 & $\mathrm{~F}$ & $67-74$ & 62 & $76-75$ & 5 & 7.1 \\
\hline 3 & $08 / 25$ & 26 & TS3 & 65 & $\mathrm{~F}$ & 71-71 & 62 & $75-75$ & 4 & 5.7 \\
\hline 4 & $08 / 30$ & 13 & SF & 67 & $\mathrm{M}$ & $70-70$ & 50 & $68-68$ & -2 & -0.3 \\
\hline 5 & $08 / 30$ & 14 & SF & 67 & $M$ & $62-62$ & 50 & $65-65$ & 3 & 4.8 \\
\hline 6 & 09/08 & 42 & TS3 & 41 & $\mathrm{M}$ & $52-52$ & 59 & $61-61$ & 9 & 17.3 \\
\hline 7 & 09/08 & 44 & TS3 & 41 & $\mathrm{M}$ & $82-81$ & 31 & $75-81$ & -1 & -1.2 \\
\hline 8 & $09 / 14$ & 35 & TS3 & 69 & $\mathrm{~F}$ & $82-83$ & 48 & $85-85$ & 2 & 2.4 \\
\hline 9 & $09 / 14$ & 36 & TS3 & 69 & $\mathrm{~F}$ & $84-84$ & 48 & $86-86$ & 2 & 2.4 \\
\hline 10 & $09 / 20$ & 26 & SS3 & 43 & $\mathrm{~F}$ & 73-70 & 50 & $69-69$ & -1 & -1.4 \\
\hline 11 & $09 / 21$ & 26 & SS3 & 71 & $\mathrm{~F}$ & $67-64$ & 53 & $65-66$ & 0 & 0 \\
\hline 12 & $09 / 21$ & 35 & SS3 & 48 & $\mathrm{M}$ & & $140 \mathrm{G}$ & $59-62$ & & \\
\hline 13 & $09 / 21$ & 36 & SS3 & 48 & $\mathrm{M}$ & & $140 \mathrm{G}$ & $63-60$ & & \\
\hline 14 & $09 / 25$ & 12 & TS3 & 33 & $\mathrm{~F}$ & $61-67$ & 43 & $62-62$ & 0 & 0 \\
\hline 15 & $09 / 27$ & 35 & BLT & 70 & $\mathrm{~F}$ & $48-53$ & 48 & $65-65$ & 15 & 30.0 \\
\hline 16 & $09 / 27$ & 36 & $\mathrm{BL}$ & 70 & $\mathrm{~F}$ & $17-22$ & 48 & 64-64 & 44 & 220 \\
\hline 17 & $09 / 28$ & 35 & SS3 & 68 & $\mathrm{~F}$ & 43-41 & 65 & 59-59 & 17 & 40.5 \\
\hline 18 & $09 / 29$ & 16 & TS3 & 68 & $\mathrm{~F}$ & $56-57$ & 42 & $65-67$ & 8 & 14.3 \\
\hline 19 & $10 / 12$ & 26 & SS3 & 61 & $\mathrm{~F}$ & 71-71 & 43 & 64-65 & -6 & -8.5 \\
\hline 20 & $10 / 16$ & 34 & TS3 & 58 & $\mathrm{~F}$ & $69-79$ & 92 & $78-70$ & 4 & 5.7 \\
\hline 21 & $10 / 16$ & 36 & TS3 & 58 & $\mathrm{~F}$ & 64-64 & 92 & $64-64$ & 0 & 0 \\
\hline 22 & $10 / 16$ & 46 & TS3 & 58 & $\mathrm{~F}$ & $82-86$ & 65 & $86-85$ & 1 & 1.2 \\
\hline 23 & $10 / 23$ & 13 & BLT & 89 & $\mathrm{M}$ & $70-75$ & 40 & $75-75$ & 3 & 4.2 \\
\hline 24 & $10 / 26$ & 24 & TS3 & 80 & $\mathrm{~F}$ & $84-84$ & 46 & $70-70$ & -15 & -17.9 \\
\hline 25 & $11 / 13$ & 13 & TE & 82 & $\mathrm{~F}$ & $44-46$ & 70 & $70-69$ & 25 & 55.6 \\
\hline 26 & $11 / 15$ & 13 & TS3 & 38 & $\mathrm{~F}$ & $14-16$ & 62 & $70-69$ & 55 & 366 \\
\hline 27 & $11 / 24$ & 11 & TS3 & 41 & $M$ & 86-81 & 46 & $79-81$ & -3 & -3.6 \\
\hline 28 & $11 / 24$ & 12 & TS3 & 41 & $\mathrm{M}$ & 75-79 & 46 & 79-79 & 2 & 2.6 \\
\hline 29 & $11 / 24$ & 22 & TS3 & 41 & $\mathrm{M}$ & $84-80$ & 46 & $72-71$ & -9 & -10.9 \\
\hline 30 & $11 / 26$ & 15 & SS3 & 70 & $\mathrm{~F}$ & 77-77 & 53 & $76-76$ & -1 & -1.3 \\
\hline 31 & $11 / 29$ & 35 & SS3 & 65 & $\mathrm{~F}$ & $56-57$ & 50 & $80-80$ & 22 & 39.3 \\
\hline 32 & $11 / 29$ & 36 & SS3 & 65 & $\mathrm{~F}$ & $77-76$ & 50 & $79-79$ & 2 & 2.6 \\
\hline 33 & $11 / 29$ & 44 & SS3 & 65 & $\mathrm{~F}$ & $69-70$ & 82 & $64-64$ & -3 & -4.2 \\
\hline 34 & $11 / 30$ & 46 & SS3 & 70 & $\mathrm{~F}$ & 70-71 & 42 & $72-73$ & 2 & 2.8 \\
\hline 35 & $11 / 30$ & 47 & SS3 & 70 & $\mathrm{~F}$ & 77-77 & 42 & $72-75$ & -2 & -2.6 \\
\hline 36 & $12 / 01$ & 16 & TS3 & 48 & $\mathrm{~F}$ & $43-48$ & 49 & 64-64 & 19 & 41.3 \\
\hline 37 & $12 / 07$ & 34 & BLT & 82 & $\mathrm{~F}$ & $82-82$ & 75 G & 77-77 & -5 & -6.1 \\
\hline 38 & $12 / 07$ & 36 & BLT & 82 & $\mathrm{~F}$ & $43-43$ & $86 \mathrm{G}$ & $66-67$ & 23 & 60.4 \\
\hline 39 & $12 / 11$ & 35 & TS3 & 51 & $\mathrm{M}$ & $83-73$ & 31 & 71-71 & -4 & -5.0 \\
\hline 40 & $12 / 11$ & 36 & TS3 & 51 & $M$ & $66-66$ & 31 & $79-63$ & 10 & 15.2 \\
\hline
\end{tabular}

Note: TS3: Osstem SA (sand-blasted and acid treated) Implant; SS3: ditto; SF:Shofu Implant; BLT: Straumann SLA (sand-blasted with large grain of alumina and acid treated) Implant ; BL: ditto; TE: ditto

Figure 1 indicates that we had more female (and aged elderly) implant patients. Fuster-Torres MA, et al. [26] also mentioned that there were more female patients than male subjects, more implants were placed in female patients than male patients. At this moment, no clear elucidation for this trend can't be made.

From figure 2, it was observed that (i) improvement in ISQ was more remarked in female patients than male ones, (ii) female patients tend to maintain original ISQ value during healing period than male ones and (iii) even lowest ISQs found in female patients were 58 scale, these were acceptable values. López AB, et al. [27] measured ISQ values during the osseointegration period and determined the factors that affect implant stability on 24 patients ( 12 women, 12 men) with a total 64 implants (10 anterior maxilla, 12 posterior maxilla, 18 anterior mandible and 24 posterior mandible). It was found that (i) the mean ISQ of all measured implants was 62.6, (ii) the lowest mean stability measurement was at 4 weeks for all bone types (60.9) and (iii) gender difference was found to be significant $(\mathrm{p}<0.05)$; women showed higher implant stability than men, which somewhat confirmed the present 
results. However, this doesn't agree with the observation that a metaanalysis of studies on reported ISQ scales for male and female subjects suggested that there is a trend for male patients to have a higher ISQ values than female ones; however, no significant difference there between was found [3].

Turkyilmaz I, et al. [28] determined the local bone density in dental implant recipient sites using Computerized Tomography (CT) and to investigate the influence of local bone density on implant stability parameters and implant success. A total of 300 implants were placed in 111 patients. The resonance frequency analysis measurements were performed with Osstell instrument immediately after implant placement, 6, and 12 months later. It was found that (i) 20 (out of 300 placed implants) were lost, meaning a survival rate of $\% .93 .3$ after three years (average $3.7 \pm 0.7$ years), (ii) the mean ISQ value for all 300 patients was $65.7 \pm 9$ ISQ and (iii) the mean ISQ value for 280 successful implant cases was $67.1 \pm 7$ ISQ, which indicated statistically significant differences $(\mathrm{p}<0.001)$.

Cornelini R, et al. [29] placed 40 implants in twenty patients with missing mandibular premolars and molars and reported that for 39 successful implants as one implant was lost, the mean ISQ values were 72 and 74.5 at implant surgery and after one year, which was not statistically significant. The follow-up study by Degidi M, et al. [30] included 802 dental implants placed in 321 patients, and minimum observation period was one year for each implant in that study and indicated that the failed implants showed a mean ISQ value of 46 , while the successfully osseointegrated implants had ISQ values around 60. Sjöström M, et al. [31] placed 192 implants after 6 months of bonegraft healing. Implant stability was measured four times using RFA for 190 implants, and they lost 20 implants, which means a survival rate of $90 \%$ during the 3 -year follow up. It was reported that (i) the ISQ value for all implants differed significantly between abutment connection $(60.2 \pm 7.3)$ and after 6 months of bridge-loading $(62.5 \pm$ $5.5)$ but were not significant between implant placement $(61.9 \pm 9.5)$ and abutment connection $(60.2 \pm 7.3)$, and also 6 months of bridgeloading (62.5 \pm 5.5$)$ and 3 years of bridge-loading (61.8 \pm 5.5 ), (ii) when comparing individual implants, the mean ISQ at placement for 170 successful implants was $62.6 \pm 11.1$ compared to $54.9 \pm 11.1$ for 20 failed implants, which indicated a significant difference and (iii) when compared to the failed implants, the higher ISQ values were found in the successful implants, and when all successful implants were considered the ISQ values slightly decreased following implant placement and then increased up to 1-year.

Similarly, for this study, the followings were calculated, based on tables 1 and 2. ISQs measured at implant placement (ISQ@I) are $69.8 \pm$ 11.7 for total, in which $71.2 \pm 9.9$ for male patients and $67.0 \pm 13.6$ for female patients, while ISQs measured at loading (ISQ@L) are $71.7 \pm 7.5$ for total, in which $72.0 \pm 7.5$ for male patients and $70.3 \pm 7.5$ for female patients. Figure 3 compares various ISQ values reported in references cited in this paper. The number in (parenthesis) indicates the reference number; "I" stands for ISQ measured at implant placement and "L" for that at loading. For the present study, open circles represent the total average \pm standard deviation, red solid marks are average \pm SD for female subjects and blue solid circles are average \pm SD for male subjects, respectively. For reference, there are additional $\Delta$ data in the figure, indicating ISQ values for the failed cases.

From figure 3, it can be said that ISQ value should have at least 60 to exhibit successful implant treatment.

\section{Conclusions}

Within limited number of implant patient cases, it was concluded

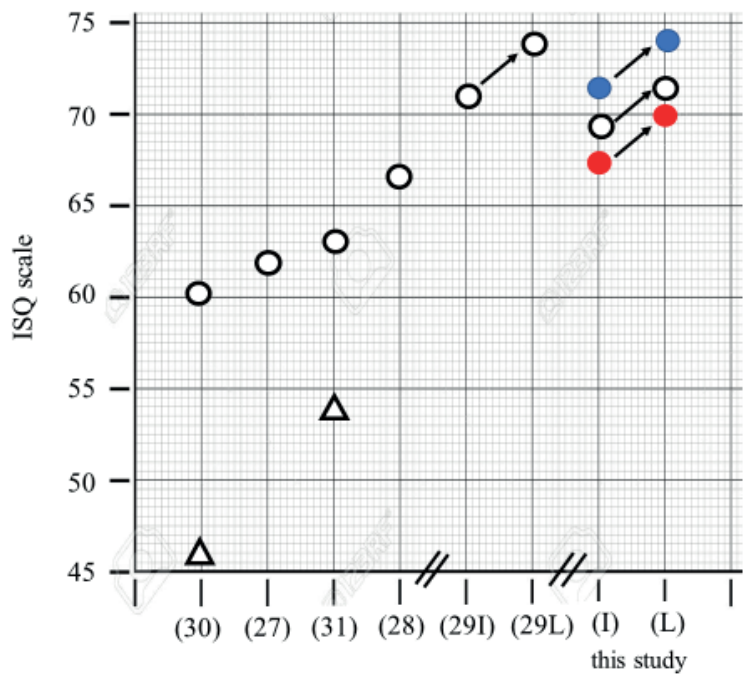

Figure 3: Comparison and changes in ISQs among various sources.

that (i) UV surface alteration and enough blood supply by piezosurgery preparation exhibited synergistic effects on improvement of ISQ scales, indicating that these dual techniques appears applicable to implant treatments, (ii) number of elderly female implant patients were more than male patients, (iii) ISQ scales increased during the bone healing stage, independent of age and gender issues, and (iv) there is a critical value of ISQ for successful implant treatment and it is at least 60 .

Minimally invasive, safe and reliable, and early functional recovery is common demands nowadays from implant patients. However, there is still a considerable risk of immediate load for both a practitioner and a patient. Even under recognized synergistic effects of piezosurgery and UV treatment, in addition to use of medium length implants, we prefer to take our standard for implant treatment to be "semi-early loading", indicating that the loading can be started sometime between one and two months after the implant placement and if ISQ exceeds always the 60 -criterion.

\section{References}

1. Miyazaki T (2020) Early Osseointegration Attained by UV-Photo Treated Implant into Piezosurgery-Prepared Site. Report I. Retrospective Study on Clinical Feasibility. Int J Dent Oral Health 6: 1-7.

2. Lekholm U, Zarb GA, Albrektsson T (1985) Patient Selection and preparation. Tissue integrated prostheses. Quintessence Publishing, Chicago 199-209.

3. Matthews MT (2014) The Impact of Gender on Dental Implant Stability Assessed Using Resonance Frequency: A Systematic Review. MS Dissertation, University of Maryland, Baltimore, USA.

4. Nordin BEC (1971) Clinical significance and pathogenesis of osteoporosis. Br Med J 1: 571-576.

5. Shiraki M, Ito H, Fujimaki H, Higuchi T (1991) Relation between body size and bone mineral density with special reference to sex hormones and calcium regulating hormones in elderly females. Endocrinol Jpn 38: 343-349.

6. Vaughn TC, Hammond CB (1981) Estrogen replacement therapy. Clin Obstet Gynecol 24: 253-283. 
7. Cha HS, Kim YS, Jeon JH, Lee JH (2013) Cumulative survival rates and complication rates of single-tooth implant; focused on the coronal fracture of fixture in the internal connection implant. J Oral Rehabil 40: 595-602.

8. Lin G, Ye S, Liu F, He F (2018) A retrospective study of 30,959 implants: Risk factors associated with early and late implant loss. $J$ Clin Periodontol 45: 733-743.

9. Negri M, Galli C, Smerieri A, Macaluso GM, Manfredi E, et al. (2014) The Effect of Age, Gender, and Insertion Site on Marginal Bone Loss around Endosseous Implants: Results from a 3-Year Trial with Premium Implant System. Journal of Biomedicine and Biotechnology. Biomed Res Int.

10. Schallhorn RA (2017) Resonance Frequency Analysis in Implant Dentistry. Journal of Multidisciplinary Care: Decision in Dentistry.

11. Pagliani L, Sennerby L, Petersson A, Verrocchi D, Volpe S, et al. (2013) The relationship between resonance frequency analysis (RFA) and lateral displacement of dental implants: an in vitro study. J Oral Rehabil 40: 221-227.

12. Uoshima K, Fujii N, Yoshida K, Nagasawa M (2008) Dental Implant Clinics. Niigata Dent J 38: 1-14.

13. Stach RM, Kohles SS (2003) A meta-analysis examining the clinical survivability of machined-surfaced and osseotite implants in poorquality bone. Implant Dent 12: 87-96.

14. Bahat O (2000) Brånemark system implants in the posterior maxilla: clinical study of 660 implants followed for 5 to 12 years. Int J Oral Maxillofac Implants 15: 646-653.

15. Chiapasco M, Gatti C, Rossi E, Haefliger W, Markwaldel TH (1997) Implant-retained mandibular overdentures with immediate loading. Clin Oral Implants Res 8: 48-57.

16. Gatti C, Haefliger W, Chiapasco M (2000) Implant-retained mandibular overdentures with immediate loading: a prospective study of ITI implants. Int J Oral Maxillofac Implants 15: 383-388.

17. Kinsel RP, Liss M (2007) Retrospective analysis of 56 edentulous dental arches restored with 344 single-stage implants using an immediate loading fixed provisional protocol: statistical predictors on implant failure. Int J Oral Maxillofac Implants 22: 823-830.

18. Fischer K, Stenberg T, Hedin M, Sennerby L (2008) Five-year results from a randomized, controlled trial on early and delayed loading of implants supporting full-arch prosthesis in the edentulous maxilla. Clin Oral Implants Res 19: 433-441.

19. Esposito M, Worthington HV, Thomsen P, Coulthard P (2004). Interventions for replacing missing teeth: different times for loading dental implants. Cochrane Database Syst Rev.
20. Esposito M, Grusovin MG, Willings M, Coulthard P, Worthington HV (2007) Interventions for replacing missing teeth: different times for loading dental implants. Cochrane Database Syst Rev.

21. Romanos GE, Nentwig GH (2006) Immediate versus delayed functional loading of implants in the posterior mandible: a 2-year prospective clinical study of 12 consecutive cases. Int J Periodontics Restorative Dent 26: 459-469.

22. De Smet E, Duyck J, Vander Sloten J, Jacobs R, Naert I (2007) Timing of loading-immediate, early, or delayed- in the outcome of implants in the edentulous mandible: a prospective clinical trial. Int J Oral Maxillofac Implants 22: 580-594.

23. Testori T, Galli F, Capelli M, Zuffetti F, Esposito M (2007) Immediate non-occlusal versus early loading of dental implants in partially edentulous patients: 1-year results from a multicenter, randomized controlled clinical trial. Int J Maxillofac Implants 22: 815-822.

24. Galli F, Capelli M, Zuffetti F, Testori T, Esposito M (2008) Immediate non-occlusal vs. early loading of dental implants in partially edentulous patients: a multicentre randomized clinical trial. Periimplant bone and soft-tissue levels. Clin Oral Implants Res 19: 546552.

25. Romanos GE, Aydin E, Locher K, Nentwing GH (2016) Immediate vs. delayed loading in the posterior mandible: a split-mouth study with up to 15 years of follow-up. Clin Oral Implants Res 27: 74-79.

26. Fuster-Torres MÁ, Penarrocha-Diago $M$, Penarrocha-Oltra $D$, Penarrocha-Diago M (2011) Relationships Between Bone Density Values from Cone Beam Computed Tomography, Mazimum Insertion Torque, and Resonance Frequency Analysis at Implant Placement: A Pilot Study. J Oral Maxillofac Implants 26: 1051-1056.

27. López AB, Martínez JB, Pelayo JL, García CC, Penarrocha M (2008) Resonance frequency analysis of dental implant stability during the healing period. Med Oral Patol Oral Cir Bucal 13: E244-E247.

28. Turkyilmaz I, McGlumphy EA (2008) Influence of bone density on implant stability parameters and implant success: a retrospective clinical study. BMC Oral Health 8: 32

29. Cornelini R, Cangini F, Covani U (2006) Immediate loading of implants with 3-unit fixed partial dentures: a 12-month clinical study. Int J Oral Maxillofac Implants 21: 914-918.

30. Degidi M, Piattelli A, Gehrke P (2006) Clinical outcome of 802 immediately loaded 2-stage submerged implants with a new gritblasted and acid-etched surface: 12-month follow-up. Int J Oral Maxillofac Implants 21: 763-768.

31. Sjöström M, Sennerby L, Nilson H (2007) Reconstruction of the atrophic edentulous maxilla with free iliac crest grafts and implants: a 3-year report of a prospective clinical study. Clin Implant Dent Relat Res 9: 46-59. 